\title{
Pre- and post-calving plasma-free amino acids in high-yielding dairy cows
}

\author{
G Piva, F Masoero, L Fiorentini, M Moschini
}

Istituto di Scienze della Nutrizione, UCSC, Faculty of Agriculture, 29100 Piacenza, Italy

Glutamine, glutamic acid, methionine, and phenyalanine are thought to be limiting amino acids in early lactating animals. A possible approach to estimate the amino-acid requirements of the very high-producing dairy cows is the measurement of the plasma-free amino-acid concentrations during early lactation. The objective of this work was to study plasma-free amino-acid concentrations in late pregnancy and early lactation in highyielding dairy cows.

Six Italian Friesian cows averaging $47.2 \mathrm{~kg} / \mathrm{d}$ of milk produced (at $45 \mathrm{~d}$ of lactation) were used in this experiment. Blood samples were collected from jugular vein at 08:00 $\mathrm{h}$ at day 15 and 5 before calving (late pregnancy), at calving, and every

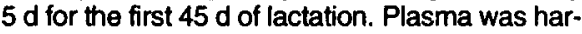
vested and analyzed for free amino-acid concentration using a Carlo Erba analyzer by the standard lithium buffer system.

Plasma-free amino-acid concentrations were lowered at calving. However, only glycine, arginine, glutamic acid, and ornithine concentrations were significantly different in early lactation (first $15 \mathrm{~d}$ ) compared to the late pregnancy period (see table I). During the first $15 \mathrm{~d}$ of lactation, plasma glutamate concentration was $26 \%$ lower, whereas lycine, omithine and arginine concentrations were higher $(39 \%, 21 \%$ and $15 \%$, respectively) compared with the later pregnancy period. A trend for a decreased concentration in glutamine $(P<0.12)$ and phenylalanine $(P<0.15)$ was observed. No significant difference was observed for plasma methionine concentration. Late pregnancy levels of almost all amino acids were restored after $25 \mathrm{~d}$ of lactation. In particular plasma concentrations of lysine, histidine and alanine were increased in the period from 15 to 45 d post partum. For ornithine and branched-chain amino acids, as expression of body protein catabolism, a positive trend was also observed $(P<0.14)$. In early lactation, the decrease in the glutamine concentration observed by Meijer was not confirmed.

Work supported by RAISA grant No 745 .

Meijer GAL, Van Der Meulen J, Van Vuuren AM (1992) Proc Biology of Lactation in Farm Animals, Madrid (Spain), 11-12 September

Table I. Plasma-free amino-acid concentrations in late pregnant and early lactating dairy cows.

\begin{tabular}{lccc}
\hline Amino acid $(\mathrm{mg} / \mathrm{l})$ & Late pregnancy & Calving - day 15 & Lactation \\
& & $3.35 \pm 0.25$ & $3.30 \pm 0.10$ \\
Met & 2.81 & $9.15 \pm 0.60$ & $11.70 \pm 0.10^{* *}$ \\
Lys & 8.45 & $49.28 \pm 2.26$ & $45.60 \pm 1.11$ \\
Gln & 43.15 & $7.15 \pm 1.20^{*}$ & $6.70 \pm 0.11^{* *}$ \\
Glu & 9.62 & $20.28 \pm 1.32$ & $25.98 \pm 2.87^{* * *}$ \\
Gly & 20.38 & $11.64 \pm 0.95^{* *}$ & $13.00 \pm 0.52^{* *}$ \\
Arg & 10.13 & $5.30 \pm 0.37^{*}$ & $9.50 \pm 0.21^{* *}$ \\
Orn & 4.39 & $9.02 \pm 0.68$ & $9.40 \pm 0.12^{* *}$ \\
His & 7.46 & $15.82 \pm 1.25$ & $20.80 \pm 0.91^{* *}$ \\
Ala & 16.49 & $7.06 \pm 1.03$ & $6.80 \pm 0.11^{* *}$ \\
Phe & 8.39 & $22.61 \pm 2.72$ & $33.90 \pm 1.10^{* *}$ \\
Val & 23.98 & $15.27 \pm 2.76$ & $19.90 \pm 3.24$ \\
Ile & 14.89 & $13.90 \pm 1.68$ & $18.70 \pm 1.78$ \\
Leu & 16.19 & $8.35 \pm 0.78$ & $9.30 \pm 1.21$ \\
Asn & 8.49 & &
\end{tabular}

Significantly different from late pregnancy (pairec $t$ test): ${ }^{*} P<0.1 ;{ }^{* *} P<0.05 ;{ }^{* * *} P<0.01$. 